\title{
Cheap vs healthy: Analyzing McDonald's menu using linear programming
}

\author{
Nur Fadhilah Ibrahim $^{1}$, Thurga Dewi Arunasalan ${ }^{2}$, Nurul Akmal Mohamed ${ }^{3}$ \\ ${ }^{1,2}$ Faculty of Ocean Engineering Technology and Informatics, University Malaysia Terengganu, Malaysia \\ ${ }^{3}$ Mathematics Department, Faculty of Science and Mathematics, Universiti Pendidikan Sultan Idris, Malaysia
}

\begin{abstract}
Article Info
Article history:

Received Sep 15, 2019

Revised Nov 1, 2019

Accepted Dec 28, 2019

\section{Keywords:}

Diet optimization

Diet problem

Fast food

Linear programming

ABSTRACT

The factors that influence food choices nowadays are time, cost and deliciousness. An obvious example is fast food. Although consumers are aware that fast food is not a healthy choice, many still chooses fast food because it is convenient. Therefore in this paper, by using linear programming, we analyzed McDonald's Malaysia menu in order to find the cheapest menu and the 'healthiest' menu. We developed a linear programming model for McDonald's Malaysia menu which adheres to Malaysia Recommended Nutrient Intake 2017 (RNI 2017). Then we solved the model and proposed the cheapest menu and also the 'healthiest' menu that meets the nutrient requirement based on RNI 2017. The result showed that price for the cheapest palatable menu is RM21.69 a day. For set menu, we found that no menu meets this requirement, suggesting that McDonald's set menu should not be taken three times a day. The price for the 'healthiest' McDonald's menu with the least total of fat, sugar and salt that meets the nutrient requirement is RM42.99 a day.
\end{abstract}

This is an open access article under the CC BY-SA license.

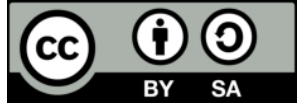

\section{Corresponding Author:}

Nur Fadhilah Ibrahim,

Faculty of Ocean Engineering Technology and Informatics,

University Malaysia Terengganu, Malaysia.

Email: fadhilah@umt.edu.my

\section{INTRODUCTION}

Diet plays an important role in human's health. We need to take sufficient nutrients to have a good health. Over nutrition or lack of nutrients may cause illness [1]. However diet requirements are not the same for everyone, they depend on age, ethnic and others. Individuals with a particular disease require different diet compared to normal people [2]. Diet requirements for children are not the same as adults [3]. Diet requirements depend on age and energy needed by specific individual. In Malaysia, Ministry of Health has published Recommended Nutrient Intake regularly as guidelines [4]. Fast food refers to food that can be prepared and served quickly. Famous fast food chains such as KFC, Pizza Hut, McDonald's, Subway, Kenny Rogers, and Burger King provide quick service, convenience, and tastes good. However, fast food is often made with ingredients such as high fat meat, refined grains, and added sugar and fats, instead of nutritious ingredients. Fast food is more flavorful and palatable because it is high in sodium which is used as a preservative.

Eating too much fast food is not good for health. A person can get obese by eating fast food regularly. British researchers from the Medical Research Council Human Nutrition Center and the London School of Hygiene and Tropical Medicine mentioned frequent intake of McDonald's, KFC or Subway meals will make people to be more likely to gain weight and become obese. Malaysia recorded an increase in its obesity rate last year, with the latest statistics showing that the overweight and obese make up nearly half of its 30 million populace. Malaysia's Health Minister has given warning that almost half the country 
population being overweight or obese. Restaurant owners can play an important role in promoting healthier choice. A study has shown that some teenage customers would choose less fat/calorie menu when nutrition information was provided when ordering food [5]. In the study, teenagers were asked to order a dinner and then they were asked again to order dinner from modified menus that contained calorie and fat content information. In another study, children would select a healthier menu if toy premiums are only offered with healthier food option [6]. By providing nutrition information and offering free toy to accompany healthier food option, customers are encouraged to choose healthier menu.

Linear programming has been used to solve diet problem since it was introduced by Stigler in 1945 [7]. The Stigler's original problem has opened the path to many minimum-cost problems such as animal feed, chemical and fertilizer blending [8]. Now, linear programming problems can be solved relatively easier with the help of faster computers compared to seventy years ago. Most of the diet problem involve minimizing the cost as it the main factor in choosing a meal [9]. The cost is minimized while following the required nutrient intake. Palatability is usually also considered. This way, people can have tasty optimal diet without burdening their finance. In Ethiopia where the populations are mostly under nutritious and stunted, linear programming was applied to produce a diet which is affordable for the lowest income [10]. In another study which focused on a rural area in Mozambique, minimum-cost porridge mix formulation is suggested in an effort to combat child malnutrition [11]. The proposed porridge mix is a big step because the conventional way of feeding the children in the area is mashed adult food that contained low energy and insufficient nutrients. In the study, no solution can be found if all the ingredients are local products. This problem was solved by adding zinc and calcium salts supplements to the children diet.

University students are also conscious of meal cost. A model for students' diet in Universiti Utara Malaysia has been developed and optimal result was obtained. The result helped the students in choosing a meal with the lowest possible cost [12]. However, in some cases, healthy food is very costly. Previous study has shown that in Armenia, people earning minimum salary need to spend more than half of their monthly income on food to afford a healthy diet [13]. While in Brazil, feasible solution was found after nutritional constraints was relaxed to meet a set of nutritional goals to reduce prevalence of inadequate nutrient intakes [14]. In another recent study in Brazil where the focus is on the low-income households, the allowable amount of nutrient increment is determined from the developed model without increasing the cost [15]. In the study, complete nutrition requirement is not achieved, however, diet quality was improved without any additional cost. In order to ensure healthy diet, a person may need to change his eating habit, but not everyone is willing to do so. A research has shown that linear programming modelling can provide a healthier menu that meet nutrient requirements without too much change from a person's current eating habits [16]. In Japan, while designing the optimal diet for Japanese adult by using linear programming [17], the researchers found that the older group needs to make minor modifications in their eating habit so that they can achieve the nutrition goal, while the younger group needs to take more fruits and vegetable in their meal. However, the participants might be highly health-conscious because almost all of them completed the study despite the strict study design. It is difficult to achieve nutritional goals for a culture-specific nutrient [18].

Different country has different gastronomical palates and cuisine choices. Thus, recommended nutrient intake may differ for different country and different time period. The application of linear programming for diet problems have been done for Malaysian case [19-21]. A healthy and palatable diet was suggested for low income female adult in Malaysia [19]. The data of the study showed that average nutrient intake for low income female adults is less than the recommended level. With the suggested menu, low income female adults can make a healthier choice. The risk of getting chronic disease can be reduced with the right choice of food [22]. Linear programming was applied in three independent studies to develop a healthy and balanced menu with minimum cost that could prevent cancer [20, 23] and anemia [24]. In recent years, the researchers have shown interest in sustainable diets [25-28]. Sustainable diets are defined as nutritionally adequate, safe and healthy, culturally acceptable, financially affordable and have low environmental impacts [29]. Food system contributes to greenhouse gas emissions (GHGEs) and thus affect climate change. GHGEs occur at every stage in the life cycle of food from primary production to processing, packaging, distribution, consumption, and waste. A study in the UK managed to provide two new diets that minimized the change in eating habit while reducing GHGEs and achieving the dietary recommendations [26]. Meanwhile a study in France managed to minimize GHGEs without compromising the dietary recommendations and at the same time affordable [25]. The main strength of the study was it considered simultaneously several dimensions of diet sustainability, namely nutritional adequacy, environmental impact, affordability and cultural acceptability.

Even when knowing the fact that eating fast food can cause many problems, this type of food is still popular. Eating meals without considering the calories or balanced nutrients will worsen the problems. Some fast food chain such as McDonald's provided nutrition information in their effort to promote balanced lifestyle. To our knowledge, no study has been done before to identify the cheapest McDonald's Malaysia 
menu that contains optimal diet. There is also no study has been done to determine the 'healthiest' menu, which is menu with the least total of fat, sugar and salt that meets the nutrient requirement. Hence, this study aims to construct the cheapest and the 'healthiest' McDonald's Malaysia menu that satisfy the Malaysia Recommended Nutrient Intake 2017 by using linear programming. This way, it is possible for the consumer to choose the cheapest menu but at the same time still meets the nutrient requirement or to choose the least harmful menu that meets the nutrient requirement.

\section{RESEARCH METHOD}

Data on nutrient intake recommendation for adult between ages 19-59 years old is gathered from Recommended Nutrient Intakes for Malaysia (RNI) 2017. Data for all McDonald's menu, price and nutrients information was obtained from McDonald's Malaysia website. There are five nutrients information provided by McDonald's Malaysia website which are carbohydrates, protein, fats, salt and sugar. However, this website does not provide the nutrients for all menu, for example, nutrients information for the new Nasi Lemak McD was unavailable. In total, the study managed to gather the required information for 104 food and beverages from the said website.

In this research, we consider that adults would require energy between $2520 \mathrm{kcal}$ and $1610 \mathrm{kcal}$, carbohydrates between $410 \mathrm{~g}$ and $210 \mathrm{~g}$, protein between $62 \mathrm{~g}$ and 52 , fats between $75 \mathrm{~g}$ and $51 \mathrm{~g}$, salt less than $5 \mathrm{~g}$ and sugar less than $50 \mathrm{~g}$ daily as in Table 1 . These requirements are based on RNI Malaysia 2017. All the food with their prices as well as upper bound and lower bound of each nutrient were filled into Microsoft Excel. Based on these data, the linear programming model is developed. Excel Solver was later used to determine the cheapest McDonald's Malaysia menu that contains optimal diet and the 'healthiest' menu, which is menu with the least total of fat, sugar and salt that meets the nutrient requirement. The linear programming model for minimizing the cost of McDonald's menus which satisfies RNI Malaysia is developed as follows:

$$
\begin{aligned}
& \operatorname{Min} \sum_{i=1}^{104} c_{i} x_{i} \\
& \text { subject to } p_{j} \leq \sum_{i=1}^{104} a_{i j} x_{i} \leq b_{j}, \\
& x_{i} \geq 0 \text { and integer, }
\end{aligned}
$$

where the variable $x_{i}$ is the number of food $i$ to be taken, $c_{i}$ is the cost of food $i, a_{i j}$ is the amount of nutrient $j$ contained in food $i, p_{j}$ is the lower bound for nutrient $j$ and $b_{j}$ is the upper bound for nutrient $j$. In this model, we wish to find the cheapest menu for a day. This can be achieved by minimizing the cost of the food for a day if McDonald's menu is considered for breakfast, lunch and dinner. The constraints of this model is the recommended amount of each nutrient that should be consumed in a day. Total for each nutrient consumed must be more than or equal to the lower bound and less than or equal to the upper bound. Now we introduce another constraint so that the menu is palatable. We limit the side dishes to three as follows.

$$
\sum x_{i} \leq 3, i \in\{\text { side dishes }\}
$$

We also limit the beverages to three as the following constraints.

$$
\sum x_{i} \leq 3, i \in\{\text { beverages }
$$

Table 1. Energy, carbohydrates, protein, fats, salt and sugar requirements per day for adults based on RNI Malaysia 2017

\begin{tabular}{ccc}
\hline Nutrient & Upper bound & Lower bound \\
\hline Energy $(\mathrm{kcal})$ & 2520 & 1610 \\
Carbohydrates $(\mathrm{g})$ & 410 & 201 \\
Protein $(\mathrm{g})$ & 62 & 52 \\
Fats $(\mathrm{g})$ & 75 & 51 \\
Salt $(\mathrm{g})$ & 5 & - \\
Sugar $(\mathrm{g})$ & 50 & - \\
\hline
\end{tabular}

If we did not consider these constraints, we may get undesirable solution such as in Table 2 where the solution gives one Beef burger, one Sausage McMuffin with Egg, one large French Fries, one small French Fries and two Sundae Cones. Many would not like to have these meals for a day. 
Table 2. The feasible but undesirable McDonald's menu that meet the nutrient requirement which cost RM21.55

\begin{tabular}{cc}
\hline Food & Number of food to be taken \\
\hline Beef burger & 1 \\
Sausage McMuffin with Egg & 1 \\
French Fries Large & 1 \\
French Fries Small & 1 \\
Sundae Cone & 2 \\
\hline
\end{tabular}

The second model is for the 'healthiest' McDonald's Malaysia menu that satisfies the RNI 2017. For this model, we minimize the total fat, sugar and salt as follows;

$$
\begin{aligned}
& \operatorname{Min} \sum_{j=1}^{3} a_{i j} x_{i} \\
& \text { subject to } p_{j} \leq \sum_{i=1}^{104} a_{i j} x_{i} \leq b_{j}, \\
& x_{i} \geq 0 \text { and integer, }
\end{aligned}
$$

where $j=1$ is fat, $j=2$ is sugar and $j=3$ is salt. Other notations are the same as the first model.

\section{RESULTS AND ANALYSIS}

The cheapest McDonald's menu for a day that satisfies the RNI 2017 is given in Table 3. This is the solution for solving problem (1) while considering the given constraint (2). The suggested menu is 2 Beef burgers, 2 apple pies, 1 Sundae Cone and a Mix\&Match set (Cheeseburger and small French Fries). The cost for the menu is RM21.69.

Table 3. The cheapest palatable McDonald's menu that meets the nutrient requirement which costs RM21.69

\begin{tabular}{cc}
\hline Food & Number of food to be taken \\
\hline Beef burger & 2 \\
Apple pie & 2 \\
Sundae Cone & 1 \\
M\&M Cheeseburger + French & 1 \\
Fries Small & \\
\hline
\end{tabular}

The total cost in Table 3 does not differ much compared to Table 2 but the menu in Table 3 is more desirable because it has 3 burgers to be taken in a day. Note that the solution does not list any drink, therefore this choice is suitable for take away. The solution for the second model is given in Table 4. It is the 'healthiest' McDonald's Malaysia menu that satisfies RNI 2017 with least total of fat, sugar and salt as modeled in problem (3). The proposed menu contained two Filet O-Fishes, one small French Fries, one large Corn Cup, one Apple pie, three cups of black coffees and Mix\&Match set (Chicken McNuggets 4pcs and a small French Fries).

\begin{tabular}{|c|c|}
\hline Food & Number of food to be taken \\
\hline Filet O-Fish & 2 \\
\hline French Fries Small & 1 \\
\hline Corn Cup Large & 1 \\
\hline Apple pie & 1 \\
\hline McCafé® Premium Roast Coffee black & 3 \\
\hline $\begin{array}{c}\text { M\&M Chicken McNuggets 4pcs + French } \\
\text { Fries Small }\end{array}$ & 1 \\
\hline
\end{tabular}

Table 4. The 'healthiest' McDonald's menu with least total of fat, sugar and salt that meets the nutrient requirement which costs RM42.99

The total of fat, sugar and salt for the menu in Table 3 is $123.1 \mathrm{~g}$ and Table 4 is $100.7 \mathrm{~g}$. Total fat, sugar and salt is reduced but the price is significantly higher. The price for the healthiest menu is almost twice the price for the cheapest menu. When only set menu is considered, there is no feasible solution exists. This means that there is no menu that meets the RNI 2017 requirement. Hence taking McDonald's set menu for breakfast, lunch and dinner in a day should be avoided. When only the lower bound is removed, there is also no feasible solution. When only the upper bound is removed, we have the solution for the suggested menu as in Table 5. 
Table 5. The cheapest McDonald's set menu when the upper bound is removed which costs RM23.97

\begin{tabular}{cc}
\hline Food & Number of food to be taken \\
\hline M\&M Cheeseburger + French Fries Small & 1 \\
McChicken McValue & 2 \\
\hline
\end{tabular}

The suggested menu in Table 5 has excess of fats, salts and sugar by $17.1 \mathrm{~g}, 2.5 \mathrm{~g}$ and $48.2 \mathrm{~g}$ respectively. The total of fats, salt and sugar for this menu is $197.8 \mathrm{~g}$. When we change the objective function to the least total of fats, sugar and salts, the solution is given as in Table 6 with the total fats, salts and sugar is $171.9 \mathrm{~g}$. The menu has excess of fats, salts and sugar by $131.1 \mathrm{~g}, 0.3 \mathrm{~g}$ and $28.5 \mathrm{~g}$ respectively. Total fats, salts and sugar is less than the solution in Table 5 but the price is a little higher. There is one limitation encountered in this study, that is only five nutrients are included in the models because their information are readily available on the McDonald's Malaysia menu which are carbohydrates, protein, fats, salt and sugar. Other nutrients such as fibre, vitamin, iron and calcium should also be considered in the models.

Table 6. The healthiest McDonald's set menu with the least total of fats, sugar and salts when the upper bound is removed which costs RM25.89

\begin{tabular}{cc}
\hline Food & Number of food to be taken \\
\hline Mm Chicken McNuggets 4pcs + French Fries s & 1 \\
Chicken McNuggets 6pcs McValue & 2 \\
\hline
\end{tabular}

\section{CONCLUSION}

In this paper we have presented the cheapest McDonald's menu and the healthiest McDonald's menu that meet the RNI 2017 requirements. First we developed the linear programming models and solved the model using Excel Solver. The menus produced are ideal for those who want to eat McDonald's food but at the same time is also conscious about health and cost

\section{ACKNOWLEDGEMENTS}

We would like to acknowledge University Pendidikan Sultan Idris (UPSI) and Ministry of Education Malaysia for sponsoring this research through FRGS.

\section{REFERENCES}

[1] H. Dai., et al., "Dietary Nutrient Intake and Obesity Prevalence Among Native American Adolescents," International Journal of Public Health Science, vol. 7, pp. 114-119, 2018.

[2] Susyani., and Desvianti., "Nutrition Counseling among Patients with Gout," International Journal of Public Health Science, vol. 6, pp. 360-364, 2017.

[3] A. Oumer., and B. Abebaw., "Determinants of Dietary Adequacy Among School Age Children in Guraghe Zone, Southern Ethiopia," International Journal of Public Health Science, vol. 8, pp. 211-218, 2019.

[4] National Coordinating Committee on Food and Nutrition (NCCFN)., "Recommended Nutrient Intakes for Malaysia," Ministry of Health Malaysia, 2017.

[5] J. A. Yamamoto , et al., "Adolescent Fast Food and Restaurant Ordering Behaviour With and Without Calorie and Fat Content Menu Information," Journal of Adolescent Health, vol. 103, pp. 244-248, 2012.

[6] E. P. Hobin., "The Happy Meal Effect: the Impact of Toy Premiums on Healthy Eating Among Children in Ontario, Canada," Can J Public Health, vol. 10, pp. 65-71, 2010.

[7] G. Sttigler., " The cost of subsistence," J. Farm Econom, vol. 25, pp. 303-314, 1945.

[8] S. G. Garille., and S. I. Gass., "Stigler's Diet Problem Revisited," Operations Research, vol. 49, pp. 1-13, 2001.

[9] M. Pasic., et al., "Linear Programming Local Cost Nutrition Optimization Model," Annals of DAAAM and Proceedings of the International DAAAM Symposium, pp. 389-390, 2011.

[10] A. B. Gurmu, et al., "Cost-minimized nutritionally adequate food baskets as basis for culturally adapted dietary guidelines for ethiopians," Nutrients, vol. 11, 2019.

[11] I. Carvalho, et al., "From Diets to Foods: Using Linear Programming to Formulate A Nutritious, Minimum-Cost Porridge Mix for Children Aged 1 to 2 years," Food and Nutrition Bulletin, vol. 36, pp. 75-85, 2015.

[12] N. Ahmad., et al., "Optimal Diet Selection for University Students using Integer Linear Programming," AIP Conference Proceedings, 2138, 2019.

[13] A. Ghazaryan., "Can Locally Available Foods Provide a Healthy Diet at Affordable Costs? Case of Armenia," Developement Studies Research, vol. 5, pp. 122-131, 2018.

[14] Q. Santos., et al., "Food Choices to Meet Nutrient Recommendations for the Adult Brazilian Population based on Linear Programming Approach," Public Health Nutrition, vol. 21, pp. 1538-1545, 2017. 
[15] E. Verly-Jr., et al., "Planning Dietary Improvements Without Additional Costs for Low-Income Individuals in Brazil: Linear Programming Optimization as a Tool for Public Policy in Nutrition and Health," Nutrition Journal, vol. 18 , no. 40, 2019.

[16] F. Vieux., et al., "Designing Optimal Breakfast for the United States Using Linear Programming and the NHANES 2011-2014 Database: A Study from the International Breakfast Research Initiative (IBRI)," Nutrients, vol. 11, pp. 1374, 2019.

[17] H. Okubo., et al., "Designing Optimal Food Intake Patterns to Achieve Nutritional Goals for Japanese Adults Through the Use of Linear Programming Optimization Models," Nutrition Journal, vol. 14, no. 57, 2015.

[18] M. Maillot., et al., "To Meet Nutrient Recommendations, Most French Adults Need to Expand Their Habitual Food Repertoire.," J Nutr, vol. 7, pp. 139-1721, 2009.

[19] R. Rajikan., et al ., "Construction of Healthy and Palatable Diest for Low Socioeconomic Female Adults using Linear Programming," International Journal on Advanced Science Engineering Information Technology, vol. 7, pp. 125-131, 2017.

[20] R. Alaini., et al., " Diet Optimization using Linear Programming to Develop low Cost Cancer Prevention Food Plan for Selected Adults in Kuala Lumpur, Malaysia," BMC Public Health, vol. 19, 2019.

[21] M. Ali., et al., " A new Diet Scheduling Model for Malaysian School Children using Zero-One Optimization Approach," Global Journal of Pure and Applied Mathematics, vol. 12, pp. 413-419, 2016.

[22] K. B. DeSalvo., et al., "Dietary guidelines for Americans," JAMA, vol. 315, pp. 457, 2016.

[23] G. Masset., et al., "Diet Optimization Methods Can Help Translate Dietary Guidelines into a Cancer Prevention Food Plan," The Journal of Nutritio, pp. 1541-1548, 2009.

[24] S. Oy., et al., "Problem Nutrients in Adolescent Girls With Anemia Versus Nonanemic Adolescent Girls and the Optimized Food- Based Recommendations to Meet Adequacy of These Nutrients in Adolescent School Girls in East Java, Indonesia," Food and Nutrition Bulletin, vol. 40, pp. 295-307, 2019.

[25] M. Perignon., et al., "How Low can Dietary Greenhouse Gas Emissions be Reduced Without Impairing Nutritional Adequacy, Affordability and Acceptability of the Diet? A Modelling Study to Guide Sustainable Food Choices," Public Health Nutrition, vol. 19, pp. 2662-2674, 2016.

[26] G. Horgan., et al., "Achieving Dietary Recommendations and Reducing Greenhouse Gas Emissions: Modelling Diets to Minimise the Change from Current Intakes," Int. J. of Behav. Nut and Phys. Act, pp. 13-46, 2016.

[27] J. Macdiarmid., et al., "Sustainable Diets for the Future: can we Contribute to Reducing Greenhouse Gas Emissions by Eating A Healthy Diet?," Am J Clin Nutr, vol. 96, pp. 632-639, 2012.

[28] G. Larrea-Gallegos and I. Vazquez-Rowe., " Optimization of the Environmental Performance of Food Diets in Peru Combining Linear Programming and Life Cycle Methods," Science of the Total Environment, p. 699, 2020.

[29] Food and Agriculture Organization of the United Nations., "Sustainable Diets and Biodiversity-Directions and Solutions for Policy, Research and Action." In International Scientific Symposium 'Biodiversity and Sustainable Diets United Against Hunger', 2010. 